Article

\title{
Irrational Beliefs and Social Adaptation of Online Sports Gamblers According to Addiction Level: A Comparative Study
}

\author{
Chul-Ho Bum ${ }^{1}$, Chulhwan Choi ${ }^{2, *}$ and Kyongmin Lee ${ }^{3}$ (I) \\ 1 Department of Sports Taekwondo, Graduate School of Physical Education, Kyung Hee University, \\ 1732 Deogyeong-daero, Giheung-gu, Yongin-si, Gyeonggi-do 17104, Korea; bch2180@khu.ac.kr \\ 2 Department of Golf Industry, College of Physical Education, Kyung Hee University, 1732 Deogyeong-daero, \\ Giheung-gu, Yongin-si, Gyeonggi-do 17104, Korea \\ 3 Department of Sports Science, Korea Institute of Sport Science, 727 Hwarang-ro, Nowon-gu, Seoul 01794, \\ Korea; dsukmlee@kspo.or.kr \\ * Correspondence: chulhwan.choi@khu.ac.kr; Tel.: +82-31-201-2737
}

Received: 1 October 2018; Accepted: 19 November 2018; Published: 21 November 2018

\begin{abstract}
The purpose of this study is to analyze the differences in psychological characteristics (i.e., irrational beliefs) and social adaptation according to a participant's level of addiction to online sports gambling (i.e., non-problem, low-risk, moderate-risk, and high-risk gamblers). A survey was completed by participants of online sports gambling, aged 19 years or older; 291 completed questionnaires were obtained and analyzed using multivariate analysis of variance (MANOVA). As results of this study, according to the level of addiction to online sports gambling, there were significant differences on people's mental state and social adaptation. Specifically, the more people are attached to a group that is exposed to high gambling addiction risk, the more they tend to become irrational while gambling, adopt an overconfident viewpoint, and overestimate their techniques. Moreover, as addiction to online sports gambling worsens, adaptation problems begin to appear in their work and family lives. This study demonstrated that people who are addicted to online sports gambling tend to find difficulties in thinking reasonably and logically and struggle to lead normal lives. By raising awareness on online sports gambling addiction, this study could suggest a way out of the difficulty.
\end{abstract}

Keywords: gambling addiction; irrational beliefs; online sports gambling; social adaptation

\section{Introduction}

The advancement of the internet has generated many changes in people's lives [1]. The sports field is no exception to such changes, and due to these changes, the popularity of sports and the size of the sports industry have become incomparable to that in the past [2]. Although people enjoy sports in a variety of ways, means of enjoying sports can, in general, be divided into actually participating in sports [3], watching sports, such as professional sports games [4], and purchasing sports-related products [5]. More specifically, online games, called eSports, have been officially recognized as new sports in international competitions [6]; additionally, sports broadcasts can be watched around the world without constraints of time or place [7], and purchasing sports-related products has become easier than before [5]. These changes caused by the internet have reached a peak with the release of high-tech devices, such as smartphones [8].

Sports gambling refers to games of predicting and betting on results of domestic and overseas sports league matches, such as soccer, basketball, baseball, and golf, which are popular among the public, where payment is awarded to the people who correctly predict the results [9]. Owing to 
the internet and the advantages of smart devices, online sports gambling offers the advantage of anonymity and not having to be present at the place of betting. However, the fact that one can access all the information available online at any desired time and place using a high-tech device can sometimes have negative consequences. More specifically, development of these advanced information communication technologies and smart devices, which are easily accessible for anyone without a verification process, has contributed to increasing the number of people that have become addicted to sports gambling [10]. Furthermore, Delaney [11] argued that sports gambling can be categorized into addiction depending on characteristics that include game frequency and wager amount. Specifically, bettors can make their wagers as high as they want in most of these games, without being limited by the kind of game or frequency, and obtain handsome returns accordingly, which can potentially lead them into gambling addiction [12].

From a cognitive perspective, previous studies have indicated that people with gambling addiction have a slightly different pattern of thinking, referring to irrational beliefs in gambling, than those without addiction [13-16]. When they reach an addiction level at which they cannot control their gambling behaviors on their own due to irrational beliefs, mental health problems begin to appear [17]; they may also depend on alcohol or drugs and, eventually, develop an addiction [18]. If they are unable to stop this behavior, the bigger problem is that they may inevitably experience significant difficulties in adjusting to work or family environment [19-21]. Most studies that have been conducted on this topic have focused on addiction to activities that can be enjoyed offline or directly in-person. However, due to the increase in the number of individuals who gamble in the easily accessible online environment as a result of developments in advanced technology as mentioned previously, the significance of research in this field has become profound. Moreover, this study goes beyond merely examining the cause-and-effect relationship between gambling addiction and other variables, which were the focus of most previous studies, by analyzing the significant differences in the psychological characteristics (i.e., irrational beliefs) and social adaptation of individuals based on their addiction level. This can raise awareness on gambling addiction and help people live a healthy life through psychotherapy.

\subsection{Theoretical Background}

\subsubsection{Gambling}

The definition of gambling differs slightly depending on the scholars or experts in the field, based on their perspective as a comprehensive concept. Gambling addiction is typically defined as a situation in which an individual is unable to stop an action on his/her own and repeats that action continuously [22]. Custer [20] identified three phases of gambling addiction, namely, winning, losing, and desperation phases, which are explained as follows. When people experience a chance victory from gambling, they derive psychological and financial gains. However, when they experience financial loss from continued gambling, they start to lose their ability to control themselves, and even feel a sense of desperation financially, physically, and psychologically. Previous empirical research has found that compared to non-problem gamblers, addicted gamblers play for money more frequently, on more activities and with greater amounts of money [23-25]. Further, addicted gamblers are more likely to be involved in continuous gambling, whereby winnings can be immediately risked again within the same session [23,25]. Specifically, according to the Diagnostic and Statistical Manual of the American Psychiatric Association [26], addicted gambling is diagnosed by the degree of symptoms: (a) a continuous or periodic loss of control over gambling; (b) a progression, in gambling frequency and amounts wagered, in the preoccupation with gambling and in obtaining money with which to gamble; and (c) continuation of gambling involvement despite adverse consequences [23]. However, social gambling for pleasure and fun can be stopped at an appropriate point [20].

In general, the phenomena that appear among gambling addicts can be largely grouped into cognitive, emotional, and social categories. Regarding the cognitive aspect, gambling addicts are under the illusion that they can stop whenever they want [27] or have the erroneous belief that they can 
win [28]. Regarding the emotional aspect, gambling addicts characteristically have low self-efficacy [29] or seek stimulation or thrills [30]. In terms of social aspects, a group with a higher addiction level has greater accessibility to gambling environments compared with groups with a lower addiction level [31-33] and was more exposed to violence from parents at a young age or from an environment of neglect [34]. People participate in gambling activities not through pressure from people's viewpoints but voluntarily through their inner thoughts and motivation [35]. Based on this perspective, it is important that we gain an understanding of the cognitive aspect of gambling addicts.

\subsubsection{Irrational Beliefs}

In terms of cognitive perception, addictive gamblers often maintain erroneous ideas, in other words, abnormal beliefs in their gambling behavior $[15,16]$. This tendency is called "irrational beliefs in gambling" or "irrational gambling beliefs" [36]. Irrational gambling beliefs include perceiving the danger of gambling as less than it really is [37], vague cognitive expectations [15], or illusions of control $[38,39]$ in which individuals believe they will eventually win if they continue despite continued loss. In this respect, $60 \%$ of people who have an erroneous way of thinking about gambling were found to bet more aggressively when they were losing than when they were winning [40]. Previous studies have revealed that gambling addicts have relatively strong irrational beliefs regarding gambling [13-16,41,42].

\subsubsection{Social Adaption}

Adjustment denotes the process of putting effort into and changing oneself to adapt to environmental changes [43]. Social adaptation, psychological adaptation, and physical adaptation are typical examples in this category [44]. In terms of social adaptation, a person's attitude, values, or thoughts have a considerable impact on how he/she adapts to a given situation [45]. Moreover, Venuleo and Marinaci argued that in most social science fields, a person's inner psychological state has an effect on his/her social adaptation and serves as an important variable for his/her living a normal and healthy life [46]. In this respect, Weissman argued that social adaptation is a very comprehensive concept that not only reflects an individual's adaptation to the social environment, but also includes performance and satisfaction with one's social role and interpersonal relationships [47]. Specifically, because an individual has various roles in society, social adaptation encompasses several adjustments including occupational, family, and recreational adaptations [48,49]. In turn, gambling addiction can lead to physical and psychological illnesses and be an obstacle to living a normal life [50]. In the end, it was found that that individuals who were incapable of self-control against gambling experienced difficulties in social adaptation [48,49].

This study grouped participants based on their level of addiction to gambling and then compared and analyzed the differences in their irrational beliefs regarding gambling and social adaptation. Hence, the proposed research questions were:

RQ1: Are there differences in irrational beliefs based on a participant's level of addiction to online sports gambling?

RQ2: Is there a difference in social adaptation based on a participant's level of addiction to online sports gambling?

\section{Materials and Methods}

\subsection{Participants}

In this study, online sports gambling refers to online games of predicting and betting on results of domestic and overseas sports league matches, such as soccer, basketball, baseball, and golf, which are popular among the public, where payment is awarded to the people who correctly predict the results.

Adults participating in online sports gambling were selected as study participants. To obtain the study sample, seven stores selling Sports Toto (sports lottery) located in Seoul and Gyeonggi Province 
in Korea were selected. Individuals leaving the lottery stores were asked if they were participating in online sports gambling, and the questionnaire was distributed to those who were bettors. The data collection lasted for 7 days during the second half of 2018, and individuals who did not want to participate were excluded from the survey. Eighteen questionnaires that were judged to have missing answers to some of the questions or as lacking reliability were excluded and a final total of 291 questionnaires were used as data for this study.

The demographic characteristics of respondents were as follows. First, 228 respondents $(78.4 \%)$ were male and $63(21.6 \%)$ were female; thus, there were considerably more men. In terms of age, 102 participants $(35.1 \%)$ were in their 30s, making up the greatest majority, followed by 98 participants $(33.7 \%)$ in their $40 \mathrm{~s}, 49(16.8 \%)$ in their 50s, and $42(14.1 \%)$ in their 20 s. In relation to participants' highest level of education completed, most survey participants had a bachelor's degree $(\mathrm{n}=174$, $59.8 \%)$, followed by a high school degree $(n=84,28.9 \%)$, and a master's or doctorate degree $(n=33$, $11.3 \%)$.

Finally, according to the purpose of this study, all survey respondents answered nine questions (each question ranged from 0 to 3 ) in terms of their addiction in the online sports gambling, and the answers were the criteria to determine who belonged to each research group as follows: non-problem less than 1 point $(n=61,21.0 \%)$, low-risk ranging 1 to 2 points $(n=55,18.9 \%)$, moderate-risk ranging from 3 to 7 points $(n=92,31.6 \%)$, and high-risk greater than 8 points $(n=83,28.5 \%)$.

\subsection{Measurement Tools}

First, the Canadian Problem Gambling Index (CPGI) developed by Ferris and Wynne [51] consists of 27 questions. Of these, nine questions belonging to the Problem Gambling Severity Index (PGSI) were modified according to the objectives of this study to examine the level of gambling addiction. The detailed questions on this scale are as follows: (a) Have you ever bet an amount that you could not handle? (b) Have you ever bet more money in order to feel the same excitement from past gambling experiences? (c) Have you ever tried gambling again in order to earn back money you lost? (d) Have you ever borrowed money or sold something in order to earn money for gambling? (e) Have you ever thought that gambling might be problematic? (f) Have you ever experienced health issues, such as stress or anxiety, due to gambling? (g) Have you ever heard people tell you that you have a problem with gambling? (h) Have you or your family experienced financial issues due to gambling? and (i) Have you ever felt guilty about gambling? This scale consists of a single factor and utilizes a 4-point Likert-type scale from "not at all" (0 points) to "always" ( 3 points). This scale categorized participants into four stages, namely, 0 points equating to non-problem gamblers, $1-2$ points for low-risk gamblers, 3-7 points for moderate-risk gamblers, and 8 points or more for high-risk gamblers. Groups with a higher score implied a stronger addiction to gambling.

Second, the measurement tool reconstructed by Lee [52] based on the Gambling Belief Questionnaire (GBQ) by Steenbergh, Meyers, May, and Whelan [53] and the scale by Langer and Roth [54] was used for irrational gambling beliefs. Irrational gambling beliefs were divided into two sub-scales "overconfidence and illogical reasoning" and "technique overestimation reasoning." The former means "considering one's capacity as greater than what it really is" or "expecting results better than what they can be in reality." The latter signifies "believing that there are regular patterns in gambling and judging that techniques or strategies matter more than luck." Overconfidence and illogical reasoning and technique overestimation reasoning comprise 7 and 6 questions, respectively, which employ a 5-point Likert-type scale ranging from "strongly disagree" (1 point) to "strongly agree" (5 points).

Third, the scale used by Shin [49] and Ahn [48] was utilized to measure social adaptation. The sub-scales are divided into workplace adaptation (4 items), home adaptation (5 items), and leisure adaptation (5 items). This measure employs a 5-point Likert-type scale that ranges from "strongly disagree" (1 point) to "strongly agree" (5 points). Additionally, since the survey respondents of this study were not fluent in English, translation/back-translation was conducted to establish semantic 
equivalence. Two bilingual professors in a sport management program were in charge of translating and back-translating survey questions to retain the original meanings.

\subsection{Data Analysis}

The SPSS 23.0 statistical version was used for data processing in this study. The details of the data processing method are as follows. First, a frequency analysis was conducted to examine the demographic characteristics of survey respondents. To verify the validity of data collected from the survey, an exploratory factor analysis (EFA) was performed on each variable (i.e., irrational gambling belief and social adaption). Also, Cronbach's alpha was conducted for a reliability analysis to test the internal consistency of the questions. After this process, a multivariate analysis of variance (MANOVA) was utilized to compare and examine the differences in irrational gambling beliefs and social adaption according to the four groups (i.e., non-problem, low-risk, moderate-risk, and high-risk gamblers) categorized by the level of addiction in online sports gambling.

\section{Results}

\subsection{Scale Validity and Reliability}

The EFA using principle component analysis (PCA) with Varimax rotation was performed on each variable. In terms of irrational gambling beliefs (13 items), the Kaiser Meyer-Olkin (KMO) measure showed the sample adequacy for this analysis, $\mathrm{KMO}=0.918$, exceeding the criteria (0.70) [55]. Bartlett's test of sphericity $\left(\chi^{2}=2823.663, d f=78, p<0.001\right)$ was statistically significant. Based on eigenvalues (greater than 1) and factor structure coefficient (greater than 0.40 ), two factors were extracted. The factors explained $71.82 \%$ of the total variance. Cronbach's alphas reported acceptable internal consistency for reliability (greater than 0.70) [56]: (a) overconfidence and illogical reasoning $(\alpha=0.936)$ and $(b)$ technique overestimation reasoning $(\alpha=0.916)$. Detailed information was shown in Table 1.

Table 1. Factor structure matrix for irrational gambling beliefs.

\begin{tabular}{|c|c|c|}
\hline Items & 1 & 2 \\
\hline I can predict the results better than other people. & 0.872 & \\
\hline I'm losing money now, but I can tell if I can win a sports game. & 0.866 & \\
\hline Since I have the techniques and knowledge of online sports gambling, I will win someday. & 0.856 & \\
\hline $\begin{array}{l}\text { Since I have a particular practice or habit when it comes to betting, I have a higher chance } \\
\text { of winning. }\end{array}$ & 0.826 & \\
\hline Since I won big a few times before, I will win big again someday. & 0.814 & \\
\hline Since I've been losing so far, I have a higher chance of winning money in the future. & 0.810 & \\
\hline If I keep betting, I will win and raise my profits. & 0.808 & \\
\hline When I bet, the results depend on my judgment. & & 0.852 \\
\hline When I won in the past, it was because I made good analyses and inferences about the game. & & 0.839 \\
\hline If I predict future games based on past game results, I'll have a higher chance of winning. & & 0.816 \\
\hline If I want to win through betting, I have to develop a good strategy. & & 0.812 \\
\hline There are often times when I think I would have won if I thought about things a little bit more. & & 0.808 \\
\hline $\begin{array}{l}\text { The money I lost so far was because I didn't have the knowledge and techniques required for } \\
\text { online sports gambling. }\end{array}$ & & 0.784 \\
\hline Eigenvalues & 6.489 & 2.848 \\
\hline Variance $(\%)$ & 49.914 & 21.906 \\
\hline Cronbach's alphas & 0.936 & 0.916 \\
\hline
\end{tabular}

With respect to social adaption, the KMO measure showed the sample adequacy for this analysis, $\mathrm{KMO}=0.863$, exceeding the criteria (0.70) [55]. Bartlett's test of sphericity $\left(\chi^{2}=1430.642, d f=91\right.$, $p<0.001$ ) was statistically significant. Based on eigenvalues (greater than 1 ) and factor structure coefficient (greater than 0.40 ), three factors were extracted. The factors explained $58.40 \%$ of the total variance. Cronbach's alphas reported acceptable internal consistency for reliability (greater than 
0.70) [56]: (a) workplace adaptation $(\alpha=0.775)$, (b) home adaption $(\alpha=0.804)$, and (c) leisure adaption $(\alpha=0.817)$. Detailed information is shown in Table 2.

Table 2. Factor structure matrix for social adaption.

\begin{tabular}{|c|c|c|c|}
\hline Items & 1 & 2 & 3 \\
\hline When I finish work and do or help with the housework, I do it gladly. & 0.780 & & \\
\hline I have a good relationship with my family. & 0.726 & & \\
\hline $\begin{array}{l}\text { When something difficult happens, I go through it with my family or I think about } \\
\text { them first. }\end{array}$ & 0.706 & & \\
\hline I tend to spend a large amount of time with my family. & 0.671 & & \\
\hline I want to take part in cultural activities with my family. & 0.669 & & \\
\hline I do other leisure activities aside from the online sports gambling I do right now. & & 0.811 & \\
\hline $\begin{array}{l}\text { I tend to get help from others or make the effort to find the information I need through } \\
\text { leisure activities aside from work or family. }\end{array}$ & & 0.772 & \\
\hline I participate in leisure gatherings frequently. & & 0.747 & \\
\hline I like meeting with people through leisure activities. & & 0.633 & \\
\hline I enjoy active leisure time aside from work. & & 0.610 & \\
\hline I have a good relationship with my work colleagues. & & & 0.818 \\
\hline I'm happy when I work at my workplace. & & & 0.789 \\
\hline Gatherings with work colleagues after work are important. & & & 0.721 \\
\hline I have a strong interest in and curiosity about my work. & & & 0.667 \\
\hline Eigenvalues & 5.038 & 1.721 & 1.416 \\
\hline Variance (\%) & 35.989 & 12.293 & 10.118 \\
\hline Cronbach's alphas & 0.804 & 0.817 & 0.775 \\
\hline
\end{tabular}

\subsection{Multivariate Analysis of Variance}

The multivariate analysis reported statistically significant differences in irrational gambling beliefs and social adaption dependent on the degree of addiction in the online sports gambling. [Wilks' lambda $=0.301, F(15,781.640)=28.418, p=0.00$, partial $\left.\eta^{2}=0.330\right]$. Based on adjusted alpha level using Bonferroni correction $(P=0.05 / 5=0.01)$, univariate tests for all variables were statistically significant: (a) overconfidence and illogical reasoning, (b) technique overestimation reasoning, (c) home adaptation, (d) leisure adaption, and (e) workplace adaption (Table 3).

Table 3. Results of multivariate analysis of variance (MANOVA) differences in irrational gambling beliefs and social adaption dependent on the degree of addiction in online sports gambling.

\begin{tabular}{cccccc}
\hline Source & DV & $d f$ & $\boldsymbol{F}$ & $\boldsymbol{p}$ & $\boldsymbol{\eta}^{\mathbf{2}}$ \\
\hline \multirow{2}{*}{ Irrational gambling beliefs } & Overconfidence and illogical & 3 & 43.859 & $0.000^{* * *}$ & 0.314 \\
& Technique overestimation & 3 & 59.300 & $0.000^{* * *}$ & 0.383 \\
\hline \multirow{3}{*}{ Social adaption } & Home adaption & 3 & 68.823 & $0.000^{* * *}$ & 0.418 \\
& Leisure adaption & 3 & 87.896 & $0.000^{* * *}$ & 0.479 \\
& Workplace adaption & 3 & 23.045 & $0.000^{* * *}$ & 0.194 \\
\hline & *** $p<001$.
\end{tabular}

Follow-up Tukey post-hoc analyses were conducted to verified where the differences existed among groups. First, the two groups with a higher risk level (moderate- and high-risk groups) showed significantly higher results in terms of overconfidence and illogical gambling beliefs compared with the two groups with a lower risk level (non-problem and low-risk groups). Of the former two groups, the high-risk gamblers group showed statistically, significantly higher levels than the moderate-risk gamblers one. Second, the non-problem gamblers group showed significantly lower average values for technique overestimation gambling beliefs than the other groups. Of the groups with high average values, the two groups with a high addiction level (i.e., moderate- and high-risk gamblers) showed higher average values than the low-risk gamblers group. Higher values for the two factors of irrational gambling beliefs imply more irrational beliefs. 
Third, the two lower risk groups (non-problem and low-risk groups) showed higher average values for leisure and workplace adaptation than the other two groups with relatively higher risk levels (moderate- and high-risk groups). Lastly, the average values for home adaptation showed a correlation with risk level among groups. In other words, higher risk groups were found to have more home adaptation issues. Table 4 shows the details on the average values of each group. Lower scores for the above three factors related to social adaptation imply social adaptation issues.

Table 4. Mean scores for irrational gambling beliefs and social adaption among groups.

\begin{tabular}{cccccc}
\hline & $\mathbf{1}$ & $\mathbf{2}$ & $\mathbf{3}$ & $\mathbf{4}$ & $\mathbf{5}$ \\
\hline Group 1 & 2.19 & 1.90 & 4.06 & 4.24 & 3.66 \\
Group 2 & 2.11 & $\mathbf{2 . 3 7}$ & 3.57 & $\mathbf{3 . 9 0}$ & 3.45 \\
Group 3 & $\mathbf{3 . 0 4}$ & $\mathbf{3 . 1 6}$ & $\mathbf{2 . 9 2}$ & $\mathbf{2 . 9 4}$ & $\mathbf{2 . 8 9}$ \\
Group 4 & $\mathbf{3 . 5 7}$ & $\mathbf{3 . 4 4}$ & $\mathbf{2 . 6 0}$ & $\mathbf{2 . 8 7}$ & $\mathbf{2 . 6 2}$ \\
\hline
\end{tabular}

Note. 1 = Overconfidence and illogical reasoning, $2=$ technique overestimation reasoning, $3=$ home adaption, 4 = leisure adaption, and 5 = workplace adaption; Group 1 = non-problem, Group $2=$ low-risk, Group 3 = moderate-risk, and Group $4=$ high-risk gamblers. Statistically significant higher mean scores between groups in bold.

\section{Discussion}

\subsection{Differences in Irrational Beliefs Based on Online Sports Game Addiction}

This study categorized online sports gamblers' addiction level into four different groups, namely, non-problem, low-risk, moderate-risk, and high-risk gamblers based on their scores on the PGSI scale. First, this study focused on comparing and analyzing the differences in irrational beliefs between these groups. The following conclusions can be made based on the results. First, moderate- and high-risk gamblers showed more overconfidence and irrational beliefs in online sports gambling than non-problem and low-risk gamblers. To elaborate, these beliefs were found to be stronger in the former than the latter group. Aside from non-problem gamblers, the three groups showed high technique overestimation. More technique overestimation was found in moderate- and high-risk gamblers than in low-risk ones. This finding is consistent with the results of previous studies that higher gambling addiction tendencies were related to more irrational beliefs [13-16,41,42].

Regarding this finding, Yi [57] argued that this type of individual believes that capacity, such as "skills" or "strategies," determines whether he or she wins or loses rather than "coincidence," and that he or she often tends to have irrational beliefs of winning the money soon because he or she has excellent capacity. These irrational beliefs about gambling cause the behavior to continue and a vicious circle is consolidated, in which those individuals who lost money through gambling lose self-control and are led into continued gambling behavior in order to recover the loss [15]. Ultimately, gambling addicts experience a negative impact on emotional aspects [17], and it is not uncommon for them to start relying on drugs or alcohol in severe cases [18]. Aron T. Beck [58], who is the founder of "cognitive therapy" argued that a person's behavior is strongly influenced by his/her thinking or belief system. Therefore, it is important to change irrational gambling beliefs and other negative belief systems in a healthy way through therapy and treatment so that people can live a healthy life that is free from activities leading to gambling addiction.

\subsection{Differences in Social Adaptation Based on Online Sports Game Addiction}

This study also compared and analyzed the effects the level of online sports gambling addiction has on social adaptation among groups. The results showed that addiction to online sports gambling has a significant effect on social adaptation. In other words, the groups with individuals who were exposed to high gambling risks showed issues with their adaptation to work, family, and leisure. Moreover, the two groups with a relatively higher risk (moderate- and high-risk) showed issues with leisure and workplace adaptation compared with the other groups. In addition, for home adaptation, issues with adaptation to family life depend on the level of risk among groups. In other words, higher 
risk groups were found to have more home adaptation issues. Moreover, unlike the other factors, even the low-risk groups showed home adaptation issues. This shows the intensity of the effects of gambling on a person's daily life even if he/she has a low level of addiction to gambling.

Most recreational gamblers who enjoy gambling for fun with their family or friends are known to be able to stop gambling at an appropriate moment [20]. However, those with a high risk for gambling addiction experience difficulties in their daily life [50]. Thus, various studies reported that it is not easy for them to adapt to society because of their gambling addiction $[19,20,59]$. This study also showed that groups at a higher risk of addiction to gambling showed difficulties in all aspects of social adaptation, which is consistent with the results of previous studies.

At this point, it is necessary to provide an answer to the fundamental question, "Why does online sports gambling addiction make social adaptation difficult?" To begin with, gambling on the internet does not differ at all from other existing gambling methods; the only difference is that the place of gambling moves from offline to online [60]. However, the convenience of the internet may potentially exacerbate a person's gambling addiction. The number of individuals experiencing online sports gambling is rapidly increasing, compared to the past, as individuals can connect to gambling websites regardless of time and place, as desired [10].

In addition, though there are certain differences in the degree of addiction in an individual gambler, it is almost impossible for them to control or regulate their will on their own [19]. Moreover, the convenience offered by the internet is an important factor that makes online sports gambling even more addictive than offline gambling. Therefore, online sports gambling, which is fast, easy, and accessible from anywhere and at any time, may cause people to fall to the risk of gambling addiction as more time passes.

\section{Conclusions}

People addicted to gambling often deny the fact that they are addicted to gambling or tend to refuse proper treatment, which makes adaptation to daily life even harder as a result. In conclusion, gambling addiction can be considered as a psychological disorder that can lead to maladjustment at work or to the destruction of families. Sports gambling, which awards payments to bettors according to the results of popular sports games, has permeated deeply into the daily lives of adults. In an environment with this social structure, the results of this study will bring useful data to inform, once again, on the harmfulness and seriousness of gambling, and the importance of education in eradication and prevention of this behavior. The authors propose that these data will be helpful in professional counseling and psychotherapy. Moreover, these findings can contribute to improving people's quality of life by building a healthy recreation culture through sports.

The following limitations were noted. This study only selected online sports gamblers. Offline gamblers were excluded as they were not part of this study. Therefore, a comparative study on both online and offline gamblers in the future may provide more insight into how the internet plays a role in gambling addiction. Additionally, to investigate the effects of sports on addicted individuals, future research should empirically compare and analyze the differences between sports gambling and other types of gambling and the factors that increase addiction severity. Finally, although this study focused on analyzing the cognitive aspects of gambling addiction, more in-depth studies that consider various facets, including emotional and social aspects of gambling addiction, need to be conducted in the future.

Author Contributions: C.-H.B. and C.H.C. conceived the research questions of this study. All authors participated in data collection, analysis, and interpretation, wrote the paper, and approved the final manuscript.

Funding: This research received no external funding.

Acknowledgments: We would like to express our gratitude to survey respondents. In addition, we would like to thank Kyung Hee University for its encouragement. Without their assistance and encouragement, we could not have completed the article successfully.

Conflicts of Interest: The authors declare no conflict of interest. 


\section{References}

1. Adamou, S.; Ntoka, L. The Impact of Digital Technologies on Academic Libraries-A Study in Greece. Available online: http://lnu.diva-portal.org/smash/get/diva2:1129431/FULLTEXT01.pdf (accessed on 27 September 2018).

2. Hutchins, B.; Rowe, D. Sport Beyond Television: The Internet, Digital Media and The Rise of Networked Media Sport; Routledge: New York, NY, USA, 2012; ISBN 9781136321115.

3. Kilpatrick, M.; Hebert, E.; Bartholomew, J. College students' motivation for physical activity: Differentiating men's and women's motives for sport participation and exercise. J. Am. Coll. Health 2005, 54, 87-94. [CrossRef] [PubMed]

4. Fink, J.; Parker, H. Spectator motives: Why do we watch if our favorite team is not playing? Sport Market. Q. 2009, 18, 210-217.

5. Nalbantis, G.; Fahrner, M.; Pawlowski, T. The demand for licensed merchandise in sports-On the purchase channel choice. J. Sport Manag. 2017, 31, 433-451. [CrossRef]

6. Pizzo, A.D.; Na, S.; Baker, B.J.; Lee, M.A.; Kim, D.; Funk, D.C. eSport vs. Sport: A comparison of spectator motives. Sport Market. Q. 2018, 27, 108-123.

7. Ko, M.; Yeo, J.; Lee, J.; Lee, U.; Jang, Y.J. What makes sports fans interactive? Identifying factors affecting chat interactions in online sports viewing. PLoS ONE 2016, 11, e0148377. [CrossRef] [PubMed]

8. Ha, J.P.; Kang, S.J.; Kim, Y.K. Sport fans in a "smart sport" (SS) age: Drivers of smartphone use for sport consumption. Int. J. Sports Market. Spons. 2017, 18, 281-297. [CrossRef]

9. Smith, G.J. Pools, parlays, and point spreads: A sociological consideration of the legalization of sports gambling. Sociol. Sport J. 1990, 7, 271-286. [CrossRef]

10. Digital Times. The Online Sports Gambling as A New Industry. 2006. Available online: http://www.dt.co. $\mathrm{kr} /$ contents.html?article_no=2004063002011659658002 (accessed on 27 September 2018).

11. Delaney, T. Basic concepts of sports gambling: an exploratory review. N. Y. Sociol. 2007, 2, 93-102.

12. Park, S.W. Illegal Sports Gambling Sites, Why Doesn't It Root Out? Available online: http:/ / www.newsis. com/view / ?id=NISX20131112_0012507028 (accessed on 20 September 2017).

13. Anderson, G.; Brown, R.I.F. Real and laboratory gambling, sensation-seeking and arousal. Brit. J. Psychol. 1984, 75, 401-410. [CrossRef] [PubMed]

14. Baboushkin, H.; Hardoon, K.; Gupta, R.; Derevensky, J. Underlying Cognitions in Gambling Behavior Among University Students. Presented at the Tenth International Conference on Gambling and Risk Taking, Montreal, QC, Canada, 1997.

15. Ladouceur, R.; Walker, R. A cognitive perspective on gambling. In Trends in Cognitive and Behavioral Therapies; Salkovskis, P.M., Ed.; John Wiley \& Sons Ltd.: New York, NY, USA, 1996; pp. 89-120, ISBN 0471961728.

16. Toneatto, T. Cognitive psychopathology of problem gambling. Subst. Use Misuse 1999, 34, 1593-1604. [CrossRef] [PubMed]

17. Kessler, R.C.; Hwang, I.; Labrie, R.A.; Petukhova, M.; Sampson, N. DSM-IV pathological gambling in the National Comorbidity Survey Replication. Psychol. Med. 2008, 38, 1351-1360. [CrossRef] [PubMed]

18. Petry, N.M.; Stinson, F.S.; Grant, B.F. Comorbidity of DSM-IV pathological gambling and other psychiatric disorders: Results from the national epidemiologic survey on alcohol and related conditions. J. Clin. Psychiatry 2005, 66, 564-574. [CrossRef] [PubMed]

19. American Psychiatric Association. Diagnostic and Statistical Manual of Mental Disorders, 4th ed.; American Psychiatric Association: Washington, DC, USA, 1994; ISBN 0890420610.

20. Custer, R.L. Profile of the pathological gambler. J. Clin. Psychiatry 1984, 45, 35-38. [PubMed]

21. Petry, N.M.; Ammerman, Y.; Bohl, J.; Doersch, A.; Gay, H.; Kadden, R.; Molina, C.; Steinberg, K. Cognitivebehavioral therapy for pathological gamblers. J. Consult. Clin. Psychol. 2006, 74, 555-567. [CrossRef] [PubMed]

22. Kim, H.N. Mind sports application plan for gambling addiction prevention. Korean J. Phys. Educ. 2017, 56, 429-440. [CrossRef]

23. Abbott, M.W. Problem and Nonproblem Gamblers in New Zealand: A Report on Phase Two of the 1999 National Prevalence Survey; Department of Internal Affairs: Wellington, New Zealand, 2001.

24. Clarke, D. Gambling and the trait of addiction in a sample of New Zealand university students. N. Z. J. Psychol. 2003, 32, 39-48. 
25. Clarke, D.; Rossen, F. Adolescent gambling and problem gambling: A New Zealand study. N. Z. J. Psychol. 2000, 29, 10-16.

26. American Psychiatry Association. Diagnostic and Statistical Manual of Mental Disorders, 4th ed.; American Psychiatry Association: Washington, DC, USA, 2000; ISBN 089042054.

27. Blaszczynski, A.; Silove, D. Cognitive and behavioral therapies for pathological gambling. J. Gambl. Stud. 1995, 11, 195-200. [CrossRef] [PubMed]

28. Sylvain, C.; Landouceur, R.; Biosvert, J. Cognitive and behavioral treatment of pathological gambling: A controlled study. J. Consult. Clin. Psychol. 1997, 65, 727-732. [CrossRef] [PubMed]

29. May, R.K.; Whelan, J.P.; Steenbergh, T.A.; Meyers, A.W. The gambling self-efficacy questionnaire: An initial psychometric evaluation. J. Gambl. Stud. 2003, 19, 339-357. [CrossRef] [PubMed]

30. Chantal, Y.; Vallerand, R. Skill verse luck: A motivational analysis of gambling involvement. J. Gambl. Stud. 1996, 12, 407-418. [CrossRef] [PubMed]

31. Adams, G.; Sullivan, A.; Horton, K.; Menna, R.; Guilmette, A. A study of the differences in Canadian university students' gambling and proximity to a casino. J. Gambl. Issues 2007, 19, 9-17. [CrossRef]

32. Hurt, H.; Giannetta, J.M.; Brodsky, N.L.; Shera, D.; Romer, D. Gambling initiation in preadolescents. J. Adolesc. Health 2008, 43, 91-93. [CrossRef] [PubMed]

33. Pearce, J.; Mason, K.; Hiscock, R.; Day, P. A national study of neighbourhood access to gambling opportunities and individual gambling behaviour. J. Epidemiol. Community Health 2008, 62, 862-868. [CrossRef] [PubMed]

34. McCormick, R. The importance of coping skill enhancement in the treatment of the pathological gambler. J. Gambl. Stud. 1994, 10, 77-86. [CrossRef] [PubMed]

35. Reith, G. Gambling and the contradictions of consumption: A genealogy of the "pathological" subject. Am. Behav. Sci. 2007, 51, 33-55. [CrossRef]

36. Gaboury, A.; Ladouceur, R. Irrational thinking and gambling. In Gambling Research: Proceedings of The Seventh International Conference on Gambling and Risk Taking: Vol. 3. Gamblers and gambling behavior; Eadington, W.R., Ed.; University of Nevada Press: Reno, NV, USA, 1988; pp. 142-163, ISBN 0942828267.

37. National Research Council (NRC). Social and economic effects. In Pathological Gambling: Acritical Review; National Academy of Science: Washington, DC, USA, 1999; pp. 156-191.

38. Griffiths, M.D. The cognitive psychology of gambling. J. Gambl. Stud. 1990, 6, 31-42. [CrossRef] [PubMed]

39. Griffiths, M.D. The role of cognitive bias and skill in fruit machine gambling. Brit. J. Psychol. 1995, 85, 351-379. [CrossRef]

40. Leopard, A. Risk preference in consecutive gambling. J. Exper. Psychol. Hum. Percept. Perform. 1978, 4, 521-528. [CrossRef]

41. Moore, S.M.; Ohtsuka, K. Beliefs about control over gambling among young people, and their relation to problem gambling. Psychol. Addict. Behav. 1999, 13, 339-347. [CrossRef]

42. Johansson, A.; Grant, J.E.; Kim, S.W.; Odlaug, B.L.; Götestam, K.G. Risk factors for problematic gambling: A critical literature review. J. Gambl. Stud. 2009, 25, 67-92. [CrossRef] [PubMed]

43. Lazarus, R.S. Patterns of Adjustment, 3rd ed.; McGraw-Hill: New York, NY, USA, 1976; ISBN 0070368023.

44. Lee, E.A. The relationships between the ecosystem variables and middle-aged men's psychological adjustment. Unpublished Doctoral Dissertation, Chonbuk National University, Jeonju, Jeollabuk-do, Korea, 2007.

45. Homer, P.M.; Kahle, H.L. A social adaptation explanation of the effects of surrealism on advertising. J. Advert. 1986, 15, 50-60. [CrossRef]

46. Venuleo, C.; Marinaci, T. The social construction of the pathological gambler's identity and its relationship with social adaptation: Narratives from members of Italian gambling anonymous and gam-anon family groups. J. Gambl. Issues 2017, 36, 138-163. [CrossRef]

47. Weissman, M.M. The assessment of social adjustment: A review of techniques. Arch. Gen. Psychiatr. 1975, 32, 357-365. [CrossRef] [PubMed]

48. Ahn, B.M. The Effects of Exercise Addiction Social Adjustment of 30 Weight Training Participants. Unpublished Master's Thesis, Department of Physical Education, Yong In University, Yong In University, Korea, 2016.

49. Shin, J.H. The Relation Between Social Adjustment and Weight-Training Participants' Exercise Addiction. Unpublished Master's Thesis, Department of Physical Education, Dankook University, Yongin, Gyeonggi, Korea, 2011. 
50. Neal, P.; Delfabbro, P.H.; O'Neil, M. Problem Gambling and Harm: Towards a National Definition; Office of Gaming and Racing, Victorian Government Department of Justice: Victoria, Australia, 2005.

51. Ferris, J.; Wynne, H. The Canadian Problem Gambling Index: Final Report; Canadian Centre on Substance Abuse: Toronto, ON, Canada, 2001.

52. Lee, H.P. The Relationship of Irrational Gambling Belief, Gambling Motive, And Risk Taking with Pathological Gambling. Unpublished Doctoral Dissertation, Korea University, Seoul, Korea, 2002.

53. Steenbergh, T.A.; Meyers, A.W.; May, R.K.; Whelan, J.P. A Self-report Gamblers' Maladaptive Beliefs: Initial Psychometric Properties. Presented at the 32nd Annual Conference of the Association for Advancement of Behavior Therapy in Washington, Washington, DC, USA, 1998.

54. Langer, E.J.; Roth, J. Heads I win, tails it's chance: The illusion of control as a function of the sequence of outcomes in a purely chance task. J. Person. Soc. Psychol. 1975, 951-955. [CrossRef]

55. Field, A. Discovering Statistics Using SPSS, 3rd ed.; Sage Publications: Thousand Oaks, CA, USA, 2009.

56. Nunnally, J.C.; Bernstein, I.H. Psychometric Theory, 3rd ed.; McGrawHill: New York, NY, USA, 1994.

57. Yi, I.H. An investigation on validity of the gambling attitudes and beliefs scale: The Korean version. Korean J. Health Psychol. 2005, 10, 531-546.

58. Beck, A.T. Depression: Causes and Treatment; University of Pennsylvania: Philadelphia, PA, USA, 1967.

59. KangwonLand. Study of Gambling Addicts in the Recovery Process, Kanwon-do, Korea, 2011. Available online: https: / / www.dbpia.co.kr/SKnowledge/ArticleDetail/NODE06276110 (accessed on 1 October 2017).

60. Gainsbury, S. Internet Gambling: Current Research Findings and Implications; Springer: New York, NY, USA, 2012; ISBN 9781461433897.

(C) 2018 by the authors. Licensee MDPI, Basel, Switzerland. This article is an open access article distributed under the terms and conditions of the Creative Commons Attribution (CC BY) license (http:/ / creativecommons.org/licenses/by/4.0/). 